International Journal of Engineering \& Technology, $7(4.20)(2018) 629-630$
International Journal of Engineering \& Technology
Website: www.sciencepubco.com/index.php/IJET
Research paper

\title{
Technical and Economic Analysis of Efficiency of Electronic Means' Quality Management
}

\author{
A.I. Gorobets ${ }^{1 *}$, A.S. Novikov ${ }^{2}$, Yu.Yu. Cheremukhina ${ }^{3}$, M.A. Nazarenko mirea ${ }^{4}$ \\ ${ }^{l}$ Russian Technological University, Moscow, Russia \\ ${ }^{2}$ Russian Technological University, Moscow, Russia \\ ${ }^{3}$ Russian Technological University, Moscow, Russia \\ ${ }^{4}$ Russian Technological University, Moscow, Russia
}

\begin{abstract} the life cycle are considered.

\section{Introduction}

Technical and economic analysis procedures are based on the available technical documentation of the production process, documented support for all stages of the product life cycle, as well as on the existing and sufficiently developed competence of personnel in the field of quality management [1-7]. In addition, it is necessary to take into account the specifics of national localization and the tradition of using standards, which differs significantly in the electronic industry and depends on the implementation of basic education of employees [8-13].
\end{abstract}

The requirements for quality assurance of technical and economic analysis of the effectiveness of electronic means at different stages of

Keywords: quality management, technical analysis of efficiency, economic analysis of efficiency, electronic means.

\section{Research method}

As a research method, the division of the life cycle of an electronic product into the following stages is used.

Stage of market research and development justification. At this stage, the formation of the level of quality of products corresponding to modern achievements of scientific and technological progress, as well as the search for principles and ways to justify the possibility and feasibility of creating new products.

Stage of product development and design. At this stage development of working design documentation, technological documentation for production of prototypes is carried out, the approval of specifications for the organization of serial or mass production is carried out.

Stage of production. At this stage, the organization of industrial production of products, parts, components in accordance with the planned tasks and the formed level of quality, as well as improving the quality of products based on experience.

The final stages are the stages of operation and disposal. (p x q y) $\operatorname{minf}(\mathrm{p})$; (q); (r)g.

\section{Results and analysis}

The following quality assurance requirements should be applied at different stages of the life cycle of electronic tools.

The main condition for ensuring high quality products at the stage of market research and development justification is the most accurate definition of customer or consumer requirements for the product for the current period and forecasting for the future.

The main objects of management in the quality system at the research stage are:

- collection and analysis of requirements of national and foreign customers and consumers;

- collection and analysis of information on the technical level and quality of national and foreign products of the same type;

- forecasting the appearance of a new product or generation of products, development of comprehensive plans and target programs for product development, enterprise development, industry development based on experience in its operation;

- complex forecasting of requirements to perspective materials, components, means of control and testing;

- economic analysis of the effectiveness of the creation of new equipment.

At the stage of development of technical, design and technological) documentation for the product is made:

- formation of a full range of functional requirements for new products in the terms of reference and the contract for the development;

- multivariate design using patent research and experience in the production, operation and repair of similar products with the choice of the optimal project;

- detailed study of the project with wide application of standardized, unified, proven components and design and technological solutions, using methods of mathematical modeling;

- confirmation of the rationality of the selected technical solutions by comprehensive testing of prototypes in conditions as close as possible to the operating conditions.

The main condition for ensuring the quality of products at the production stage is its production in strict accordance with technical documentation. For this purpose at production of production it is carried out:

- application of progressive saving and environmentally friendly 
technologies;

- parallel to product development preparation of serial production, including technological training, personnel training, development of new technical parameters;

- implementation of a comprehensive system of technical control, from input control of materials and components to acceptance of the finished product;

- application of methods and means of control and testing to ensure the required accuracy and reliability of the results;

- certification of organizational and technical level of production and certification of products;

- timely removal from production of obsolete products.

At the stage of operation, the products are put into operation, while at the same time:

- training and education of personnel in the techniques and methods of operation of new products;

- organization of the system of maintenance and quality control of products;

- maintenance of product quality during operation and satisfaction of claims;

- supervision of products by the manufacturer;

- improvement of products in operation;

- creation of a system of information on the quality and reliability of products in operation.

Especially important is the timely receipt of objective information on safety and reliability indicators, complaints, failure rate and other defects.

\section{Conclusion}

Quality indicators provided for in the project should clearly and unambiguously reflect the criteria for acceptance and rejection of products. Acceptance criteria that ensure the evaluation of the product include: operational data, tolerances and characteristics, test and measurement methods, requirements for the accuracy of the equipment. In the process of product development, the project is periodically evaluated at the most important stages of product development. At the end of each stage of the project development, a critical analysis of the design results is carried out. The quality system should also include the possibility of making changes to the project based on the experience gained in the process of production and operation.

Planning of the production process should provide for consistent control of the production mode: control of materials, equipment, processes and technology, mathematical support, personnel, working conditions, material supply. The quality system should also include a qualified check of special technological processes, which have particularly high requirements for working conditions. Evaluation of production stability is carried out in the framework of product certification or certification of production and quality system, taking into account the specifics of production. As experience shows, the functioning of the quality system creates a favorable psychological climate in the enterprise: the processes are carried out without interference, errors and deviations, improved cooperation between departments of the enterprise, there is a more conscious attitude to quality assurance in all employees, and new ones are quickly included in the production process.

\section{References}

[1] Kudzh, S.A., Kochetkova, L.N., Nazarenko, M.A. (2015) The philosophy of quality management // Russian Technological Journal, 3(8), (pp. 1-8).

[2] Kruchinin, S.V., Bagrova, E.V., Nazarenko, M.A. (2018). Key Ways of Information Technologies for Self-Education Development. Pros and Cons // Proceedings of the 2018 International Conference "Quality Management, Transport and Information Security, Information Technologies", IT and QM and IS, 8544901, (pp. 663 $665)$.
[3] Djevello E.S., Vlasova I.N., Larionov E.I. etc. (2018). Specifics of Management Quality Implementation to Information Systems and Products // Proceedings of the 2018 International Conference "Quality Management, Transport and Information Security, Information Technologies", IT and QM and IS, 8524995, (pp. 40-43).

[4] Kruchinin, S. V., Bagrova, E. V., \& Nazarenko, M. A. (2018, September). Simultaneous Development of E-Learning in Russia and Information Society. In 2018 IEEE International Conference" Quality Management, Transport and Information Security, Information Technologies"(IT\&QM\&IS) (pp. 666-668). IEEE.

[5] Filippov, A. A., Antonova, A. A., Antonova, I. I., Baranova, I. A., \& Nazarenko, M. A. (2018, September). Algorithm of End-to-End Integrated Quality Management. In 2018 IEEE International Conference" Quality Management, Transport and Information Security, Information Technologies"(IT\&QM\&IS)(pp. 44-46). IEEE.

[6] Nazarenko, M. A. (2018, September). Mobile Operating Systems and Integrated Apps Quality Management System. In 2018 IEEE International Conference" Quality Management, Transport and Information Security, Information Technologies"(IT\&QM\&IS) (pp. 63-65). IEEE.

[7] Muraviev, V. V., Baranova, I. A., Bykova, E. V., Khronusova, T. V., \& Nazarenko, M. A. (2018, September). Company Life Cycle and Quality Standardization. In 2018 IEEE International Conference" Quality Management, Transport and Information Security, Information Technologies"(IT\&QM\&IS) (pp. 59-62). IEEE.

[8] Khronusova T.V., Nazarenko M.A., Tarasov V.Y., Lamm M.A. (2015). Specifics of Web search query in Russian Internet // Russian Technological Journal, 4(9), ( pp. 378-385).

[9] Bagrova, E. V., Kruchinin, S. V., \& Nazarenko, M. A. (2018, September). Usage of Information Technologies in Self-Education in Russia. In 2018 IEEE International Conference" Quality Management, Transport and Information Security, Information Technologies"(IT\&QM\&IS) (pp. 565-567). IEEE.

[10] Kruchinin, S. V., Bagrova, E. V., \& Nazarenko, M. A. (2018, September). Main Self-Educational Platforms in Russia and Skills that Can Be Develop Via Them. In 2018 IEEE International Conference" Quality Management, Transport and Information Security, Information Technologies"(IT\&QM\&IS)(pp. 669-671). IEEE.

[11] Bagrova, E. V., Kruchinin, S. V., \& Nazarenko, M. A. (2018, September). Additional Education in Russia. Ways of Development. In 2018 IEEE International Conference" Quality Management, Transport and Information Security, Information Technologies" $^{\prime \prime}(I T \& Q M \& I S)$ (pp. 561-564). IEEE.

[12] Kruchinin, S. V., Bagrova, E. V., \& Nazarenko, M. A. (2018, September). Key Ways of Information Technologies for Self-Education Development. Pros and Cons. In 2018 IEEE International Conference" Quality Management, Transport and Information Security, Information Technologies"(IT\&QM\&IS)(pp. 663-665). IEEE.

[13] Nazarenko, M. A., \& Khronusova, T. V. (2017, September). Big data in modern higher education. Benefits and criticism. In "Quality Management, Transport and Information Security, Information Technologies"(IT\&QM\&IS), 2017 International Conference (pp. 676-679). IEEE. 